\title{
Exploration of Teaching Reform of Drawing Courses in Chinese Colleges and Universities Based on the Advanced Engineering Education Model ${ }^{1}$
}

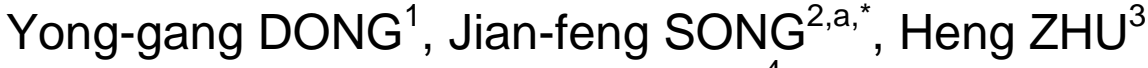 \\ and Guo-ling $\mathrm{LUO}^{4}$ \\ ${ }^{1,2,3,4}$ College of Mechanical Engineering, Yanshan University, \\ Qinhuangdao, China, 066004 \\ asongjianfeng@ysu.edu.cn
}

Keywords: Drawing courses, Teaching Reform, OBE, Team Project, Discussing Class.

\begin{abstract}
With the development of AMT (Advanced Manufacturing Technology), the greater demands have been placed on the Chinese higher education system in recent years. Characteristics of drawing courses in Chinese colleges and the advanced engineering education mode---OBE (Outcomes-based Education) were introduced firstly, and the requirements of AMT for the reform of drawing courses were presented. Moreover, the existing problems in traditional teaching model were listed, and the reform plans based on the discussing class and team project were proposed. In addition, the implementation details of teaching reform of drawing courses were given. In the end, the teaching reform practice was accomplished in Yanshan University and the students' achievements based on the discussing class and team project were shown in this paper.
\end{abstract}

\section{Introduction}

Development and application of AMT (Advanced Manufacturing Technology) depends on the ability of human beings, such as studying ability, abstracting ability and creativity etc. Therefore, it is the ultimate aim for Chinese higher education system to cultivate some people who have the abilities of innovation, creation and active learning ability by themselves.

Face to the challenge of Advanced Manufacturing Technology, Chinese engineering education system have had to be reformed in following three aspects, education concept, education thoughts and education mode. The traditional education concept is focus on teaching theoretical knowledge to the student, and the student is just a passive role to accept the abstract knowledgeable and most of students don't know how to solve the engineering problems by the theoretical knowledge. So it is difficult for the most of graduated students to meet the requirements of their work unit for lacking engineering application skills [1].

Therefore, it is necessary and indispensable to strengthen the engineering practice and engineering application training during the teaching process by setting up practice unit in the lesson.

In addition, during the process of teaching and studying, the "spoon - feeding" teaching style should be given up, and the curiosity and activity of students should be inspired to study and think actively by themselves by reasonable arrangements of

\footnotetext{
${ }^{1}$ Sponsored by Teaching Reform Project of Yanshan University(JG2016ZX03)
} 
teaching contents and practice training. Undoubtedly, this is a effective way to improve the creativity and innovation ability of students.

\section{Characteristic of Drawing Courses in Chinese Colleges and Its Teaching Mode}

\section{Characteristics of Drawing Courses in Chinese Colleges}

The drawing class is a foundation course for corresponding major or subject, and it is an important technical foundation course for students studying in colleges of science and engineering, especially for the students whose major is mechanical engineering or similar major. This courses aims at cultivating the drawing ability and the ability of reading the engineering drawings. Therefore, the drawing courses are compulsory in Chinese colleges of science and engineering, and the class hour is between 60 hours and 90 hours and its credit is between 3.5 and 5.5.

\section{Teaching Mode of Drawing Courses}

Teaching mode of drawing courses include classroom teaching, homework practice, exercises tutorials and drawing practice. General speaking, the number of students is not greater than 60 and this course will be taught two times a week.

\section{Test Method of Drawing Courses}

This courses will be examined by the way of closed book, and the contents of the test include adding the third view according to the two given views of complex forms, standard parts and common parts, reading the part drawing, apart and drawing some parts from an assembly drawing of equipment. The number of examination questions is generally 7 , and the full marks of these courses are from the test paper without any regular grades or performance points.

\section{Reform Practice of Teaching Mode on the Drawing Courses of Chinese Colleges Problems Existed in the Transitional Teaching Mode of Drawing Courses in Chinese Colleges}

In traditional teaching mode, the process of teaching and studying always revolve around the teaching program, and the teaching contents are restricted by the teaching program and corresponding knowledge points. During the whole activity of teaching and studying, the participation degree of students and the flexibility of teaching schedule are all low. After the courses have been finished, some students don't know how to choose suitable drawing methods to express the complex engineering parts reasonably and flexibly. Moreover, some students don't recognize the importance of national standard of China and corresponding industry standard, and there are lots of common mistakes in their drawings which can't reach the requirements of engineering application [2, 3].

\section{Requirements for the Reform of Drawing Courses Based on the OBE Engineering Education Mode}

Outcomes-based Education mode originated from the reform of basic education in United States and Australia. Originally speaking, OBE model spread around the mail line as "define outcomes-realize outcomes-evaluate outcomes", and the evaluation of outcomes from the students' studying is the ultimate aim to realize the continuous improvement of teaching effect. Researcher Richard from United States presented a 
design model of courses based OBE mode, and the performance evaluation of students' studying was one of three important factor of this model $[4,5]$.

According to the OBE mode, the education aim is prior to the teaching contents, and teachers can set up teaching unit by themselves without the rigid restriction of the teaching program[6].It is very important for teachers to predict and evaluate the outcomes of students' studying in this mode. Requirements of this mode for reform of drawing courses include four aspects as following:

1. Pay more attention to cultivate the manual dexterity, team cooperation ability and innovation ability of students;

2. Change the constant test method by one examination paper and evaluate studying performance and outcomes of students in different teaching unit by examining the expected ability in these courses.

3. Emphasize the cultivation of engineering application ability of students;

4. Improve the student's abilities such as autonomic study ability, communication skills and verbal dexterity by the open type team project and discussing class without fixed model answer.

\section{Reform Practice of Drawing Courses in Yanshan University}

The OBE model has been applied and popularized to the reform of advanced engineering education system in Chinese colleges and universities for several years. In recent years, the CDIO and OBE mode have been expanded in the College of Mechanical Engineering of Yanshan University for the Education Reform, and the team project and discussing class project have been added in all the profession courses. Moreover, PowerPoint presentations for the project and discussing class have already been a regular part of profession courses. Drawing department of college of mechanical engineering has carried out the reform of drawing courses since 2012, and the blue print of reform has been determined in 2016 by several years' reform practice.

\section{Reform of Teaching Mode}

1. Set up the discussing class for the comprehensive expression of complex typical solid parts without a constant answer, and Encourage students to express it by different expression plans which accords with the national standards. Exercise the use of measuring devices and the flexible application of expressing methods, and cultivate the ability of finding and solving the questions by information retrieving and team discussing.

2. Set up group project for the measuring and drawing of assembly solid body, and deepen the students' comprehension on common assembly structure and standard parts and common parts by taking apart and assembling the equipment.

\section{Reform of Performance Evaluation Contents and Methods}

1. Evaluation contents include homework (10 points), discussing class (10 points), team project (10 points) and examination paper (70 points);

2.In examination paper, the first question is comprehensive expression of the complex parts with a given axon metrical projection, the full point this question is no less than 20 and not greater than 30, and it is just needed to give the drawing without the size and technical specifications. The second question is reading the parts drawing, the full point of this question is about 20 , students are demanded to fill the blanks and draw 
a view or sectional view not given. The last question is parting the equipment and presenting the parts drawing, and the figures, sizes, tolerances, roughness and technical specifications. In addition, the knowledge of common parts and standard parts will be tested in the team project and discussing class.

\section{Achievements of Reform in Drawing Courses}

Some achievements from the discussing class and team project were shown in Fig. 1 and Fig.2. As shown in Fig.1 and Fig.2, students grasp the basic drawing skills and can accomplish the engineering drawing as expected.

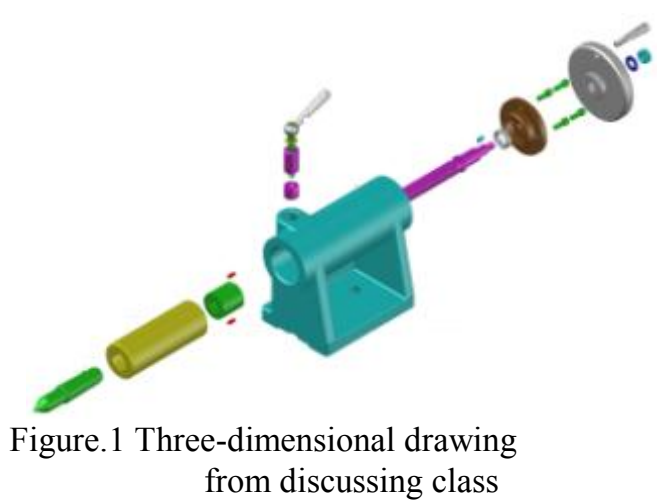

from discussing class

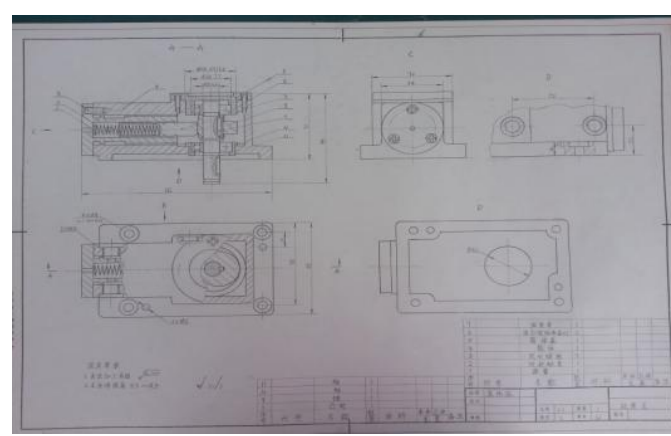

Figure.2 Two-dimensional assembly drawing from team project

\section{Acknowledgment}

This research was financially supported by the Teaching Reform Project of Yanshan University (JG2016ZX03).

\section{References}

[1] Z. Li, F. Lin. Development trend of engineering education with a view of engineering's essence, Research on the advanced engineering education, 13(2007)17-21(in Chinese)

[2] Y. Xie. Reform on the development mode and management of Chinese engineering education courses, Research on the advanced engineering education.3 (2016) 34-38(in Chinese)

[3] X. Bai. Research on the cultivation mode of entrepreneurial engineering talents in Chinese colleges and universities.2011, Wuhan: Doctoral Dissertation of Huazhong University of Science and Technology in Chinese)

[4] Y. Hai. Reform practice and analyze on the regional engineering colleges and Universities based on the OBE mode. Contemporary education theory and its practice. (2015)37-39(in Chinese)

[5] P. Gu, W. Hu. Engineering education mode based on "Outcomes-based education"_-practice and exploration on the education reform in Shantou University, Research on the advanced engineering education.11 2014)27-37(in Chinese)

[6] X. Chen, G. Dai. Discussion about constructing the evaluation system of overall qualities for under graduate students in Chinese college and universities with a view of 
OBE engineering education mode. Zhe Jiang University of Technology (Social Science edition). 4(2015)464-467(in Chinese) 